\title{
Espaço (hi) Ato: Práticas assistenciais na internação psiquiátrica em hospital especializado
}

\author{
Gap - Act Position: Assistance practices in psychiatric hospitalization in a specialized hospital \\ Espacio - Pausa: Prácticas de asistencia en hospitalización psiquiátrica en hospital especializado
}

Recebido: 24/06/2021 | Revisado: 30/06/2021 | Aceito: 02/08/2021 | Publicado: 07/08/2021

\author{
Aline Porto Reis \\ ORCID: https://orcid.org/0000-0003-0890-7558 \\ Universidade Federal do Rio de Janeiro, Brasil \\ E-mail: alinenila@gmail.com \\ Cristina Maria Douat Loyola \\ ORCID: https://orcid.org/0000-0003-2824-6531 \\ Universidade CEUMA, Brasil \\ E-mail: crisloyola@hotmail.com \\ Claudia Barbastefano Monteiro \\ ORCID: https://orcid.org/0000-0002-3150-7424 \\ Universidade Federal do Rio de Janeiro, Brasil \\ E-mail: claudia.ipub@gmail.com
}

\begin{abstract}
Resumo
Objetivo: O artigo teve como objetivo analisar a percepção do profissional sobre o impacto da sua atuação no cuidado aos usuários internados em um hospital especializado em psiquiatria. Método: Pesquisa qualitativa etnográfica onde, como profissional do local em questão, pude atuar como observadora participante, com a utilização de um diário de campo e realização de 25 entrevistas semiestruturadas até a saturação teórica com profissionais da equipe da enfermaria visando captar o plano do discurso institucional e as contradições existentes nas diferentes percepções sobre o cuidado nesta instituição. Resultado e discussão: Os resultados dessa pesquisa mostraram que o cuidado prestado pelo profissional médico ainda é centrado na racionalidade cientifica moderna, na biomedicina e no biopoder. O cuidado ainda é voltado para a resolutividade e a noção de "cura" produz mal-estar profissional na medida em que a cronificação se mostra como falência dos esforços terapêuticos. Falta equipe interdisciplinar para construir uma outra forma de cuidar, ainda permanece, numericamente, a velha dupla do hospício, enfermagem e médicos. Alguns profissionais atuaram pautados pela lógica da atenção psicossocial embora dificultados pela configuração dos processos de trabalho, e pela rigidez das rotinas. Conclusão: A busca por um novo fazer na clínica, possibilitou uma compreensão mais ampliada da vivência de quem sofre. Neste sentido, refletir sobre o que baliza este novo cuidado e esta nova clínica nos colocou em um lugar de constante busca e compreensão.
\end{abstract}

Palavras-chave: Saúde Mental; Hospital Psiquiátrico; Reforma Psiquiátrica; Atenção Psicossocial; Processo assistencial.

\begin{abstract}
The article aims to analyze the perception of the professional about the impact of his performance in the care of users admitted to a hospital specialized in psychiatry. Qualitative ethnographic research where, as a professional of the place in question, I was able to act as a participating observer, using a field diary (totaling $80 \mathrm{~h}$ ) and conducting 25 semi-structured interviews until theoretical saturation with professionals from the infirmary team in order to capture the institutional discourse plan and the contradictions existing in the different perceptions about care in this institution. The results of this research showed that the care provided by the medical professional is still centered on modern scientific rationality, biomedicine and biopower. Care is still focused on resolvability and the notion of "cure" produces professional malaise as the chronification shows itself as a failure of therapeutic efforts. An interdisciplinary team is lacking to build another form of care, the old pair of hospices, nurses and doctors still numerically remains. There are professionals whose work is guided by the logic of psychosocial care, although hampered by the configuration of work processes and the rigidity of routines. The search for a new practice in the clinic, allows a broader understanding of the experience of those who suffer. In this sense, reflecting on what guides this new care and this new clinic puts us in a place of constant search and understanding.
\end{abstract}

Keywords: Mental health; Psychiatric Hospital; Psychiatric Reform; Psychosocial Care; Assistance process.

\section{Resumen}

El artículo tiene como objetivo analizar la percepción del profesional sobre el impacto de su desempeño en la atención de los usuarios ingresados en un hospital especializado en psiquiatría. Investigación etnográfica cualitativa donde, como profesional del lugar en cuestión, pude actuar como observador participante, utilizando un diario de campo y 
realizando 25 entrevistas semiestructuradas hasta la saturación teórica con profesionales del equipo de enfermería. con el fin de captar el plan institucional del discurso y las contradicciones existentes en las distintas percepciones sobre el cuidado en esta institución. Los resultados de esta investigación mostraron que la atención brindada por el profesional médico aún se centra en la racionalidad científica moderna, la biomedicina y el biopoder. El cuidado sigue centrado en la resolubilidad y la noción de "curación" produce malestar profesional ya que la cronificación se manifiesta como un fracaso de los esfuerzos terapéuticos. Falta un equipo interdisciplinario para construir otra forma de atención, la pareja de ancianos del hospicio, enfermería y médicos aún permanece numéricamente. Hay profesionales cuyo trabajo está guiado por la lógica de la atención psicosocial, aunque obstaculizado por la configuración de los procesos laborales y la rigidez de las rutinas. La búsqueda de una nueva práctica en la clínica permite una comprensión más amplia de la experiencia de quienes la padecen. En este sentido, reflexionar sobre lo que guía esta nueva atención y clínica nos coloca en un lugar de búsqueda y comprensión constante.

Palabras clave: Salud mental; Hospital Psiquiátrico; Reforma Psiquiátrica; Atención Psicosocial; Proceso de asistencia.

\section{Introdução}

Há 18 anos foi aprovada a Lei no 10.216/2001, conhecida como Lei da Reforma Psiquiátrica Brasileira (RPb), que trata sobre os direitos das pessoas em sofrimento psíquico e da reorientação do modelo assistencial. Ao longo desse período observou-se transformações e avanços no cenário assistencial do país.

Por décadas, o atendimento ao doente mental no Brasil esteve ligado ao modelo centrado no hospital, cujo tratamento limitava-se a internações prolongadas, mantendo o doente afastado do âmbito familiar e social.

Os Centros de Atenção Psicossocial (CAPS) foram implantados, como resultado daquele movimento, para articularem a Rede de Saúde Mental e o território onde estão implantados. Os CAPS situam-se como serviços substitutivos aos hospitais psiquiátricos, que têm por objetivos: dar atendimento clínico diário, a fim de evitar as internações; promover a inserção social das pessoas com transtornos mentais; constituir-se em porta de entrada à rede de atenção especializada; e proporcionar suporte em saúde mental, focando no desenvolvimento de autonomia (Brasil, 2005) .

Toda a estratégia de Saúde Mental deveria ser desenvolvida no âmbito da Rede de Atenção Psicossocial - RAPS, aprovada pela Portaria $n^{\circ} 3.088 / 2011$, que visa o fortalecimento das ações e serviços oferecidos às pessoas com transtornos mentais e com necessidades decorrentes do uso de drogas (Brasil, 2011).

Entretanto, não há como negar possíveis reformulações nessas conquistas, especialmente com as mudanças ocorridas na Coordenação Nacional de Saúde Mental e na condução da política de atenção psicossocial no país a partir de 2016 (Amarante \& Nunes, 2018).

Exatamente 30 anos após a publicação da "Carta de Bauru", documento que é um marco na luta antimanicomial no Brasil, a política de saúde mental sofre mudanças que validam distorções e retrocessos na implantação da Reforma Psiquiátrica no país. No plano micropolítico, observou-se dificuldades quanto à ruptura de práticas profissionais que afirmam a objetificação do portador de sofrimento psíquico, a supressão do sintoma, os especialismos, a demanda por internação, a não continuidade do cuidado, a ambulatorização da assistência, enfim, processos de trabalho que acabaram mantendo a cultura manicomial vigorosa (Sampaio, Guimarães, Carneiro, \& Garcia Filho, 2011).

Sendo assim, este projeto de pesquisa teve como objeto de estudo as práticas assistenciais oferecidas às pessoas em sofrimento psíquico internadas em hospital especializado em psiquiatria. Justificou-se por ser um tema atual, uma vez que os hospitais psiquiátricos na prática nunca estiveram fora do circuito assistencial da rede, e que neste momento político ganharam maior incentivo para fortalecimento de suas atuações.

As práticas assistenciais aos sujeitos em sofrimento psíquico em situação de crise, que por algum motivo necessitam de internação em um hospital psiquiátrico, foram decisivas para a relação de cuidado. Nesta relação, diversas estratégias de atuação puderam contribuir para que, diante do pressuposto da lógica da atenção psicossocial, fosse possível a construção da autonomia mediante responsabilização compartilhada e pactuada entre os sujeitos, os serviços e a comunidade. 
O cuidado ao sujeito possibilitou explorar potências que puderam ser estabelecidas a partir de práticas assistenciais construídas entre a equipe que atuou no momento da internação. Foi importante, portanto, priorizar o acolhimento, a autonomia e a troca direta com as experiências de vida do indivíduo que possui um lugar no mundo, uma história.

O objetivo deste trabalho, portanto, foi analisar as práticas assistenciais oferecidas às pessoas em sofrimento psíquico durante internação em hospital especializado em psiquiatria. Tal estudo visou contribuir com a reflexão acerca do cuidado prestado aos sujeitos internados nos hospitais psiquiátricos e do aprimoramento deste cuidado a partir do questionamento do modelo assistencial institucional. Os diferentes modelos assistenciais possibilitaram reconfigurar a lógica de atenção psicossocial, a partir de práticas asilares ou ampliá-las à medida que sejam pautadas no diálogo com a RAPS e seus pressupostos de singularização e territorialização do cuidado.

\section{Metodologia}

Há 18 anos foi aprovada a Lei ${ }^{\circ}$ 10.216/2001, conhecida como Lei da Reforma Psiquiátrica Brasileira ( $\left.\mathrm{RPb}\right)$, que trata sobre os direitos das pessoas em sofrimento psíquico e da reorientação do modelo assistencial. Ao longo desse período observou-se transformações e avanços no cenário assistencial do país.

Por décadas, o atendimento ao doente mental no Brasil esteve ligado ao modelo centrado no hospital, cujo tratamento limitava-se a internações prolongadas, mantendo o doente afastado do âmbito familiar e social.

Os Centros de Atenção Psicossocial (CAPS) foram implantados, como resultado daquele movimento, para articularem a Rede de Saúde Mental e o território onde estão implantados. Os CAPS situam-se como serviços substitutivos aos hospitais psiquiátricos, que têm por objetivos: dar atendimento clínico diário, a fim de evitar as internações; promover a inserção social das pessoas com transtornos mentais; constituir-se em porta de entrada à rede de atenção especializada; e proporcionar suporte em saúde mental, focando no desenvolvimento de autonomia (Brasil, 2005) .

Toda a estratégia de Saúde Mental deveria ser desenvolvida no âmbito da Rede de Atenção Psicossocial - RAPS, aprovada pela Portaria n ${ }^{\circ} 3.088 / 2011$, que visa o fortalecimento das ações e serviços oferecidos às pessoas com transtornos mentais e com necessidades decorrentes do uso de drogas (Brasil, 2011).

Entretanto, não há como negar possíveis reformulações nessas conquistas, especialmente com as mudanças ocorridas na Coordenação Nacional de Saúde Mental e na condução da política de atenção psicossocial no país a partir de 2016 (Amarante \& Nunes, 2018).

Exatamente 30 anos após a publicação da "Carta de Bauru", documento que é um marco na luta antimanicomial no Brasil, a política de saúde mental sofre mudanças que validam distorções e retrocessos na implantação da Reforma Psiquiátrica no país. No plano micropolítico, observou-se dificuldades quanto à ruptura de práticas profissionais que afirmam a objetificação do portador de sofrimento psíquico, a supressão do sintoma, os especialismos, a demanda por internação, a não continuidade do cuidado, a ambulatorização da assistência, enfim, processos de trabalho que acabaram mantendo a cultura manicomial vigorosa (Sampaio, Guimarães, Carneiro, \& Garcia Filho, 2011).

Sendo assim, este projeto de pesquisa teve como objeto de estudo as práticas assistenciais oferecidas às pessoas em sofrimento psíquico internadas em hospital especializado em psiquiatria. Justificou-se por ser um tema atual, uma vez que os hospitais psiquiátricos na prática nunca estiveram fora do circuito assistencial da rede, e que neste momento político ganharam maior incentivo para fortalecimento de suas atuações.

As práticas assistenciais aos sujeitos em sofrimento psíquico em situação de crise, que por algum motivo necessitam de internação em um hospital psiquiátrico, foram decisivas para a relação de cuidado. Nesta relação, diversas estratégias de atuação puderam contribuir para que, diante do pressuposto da lógica da atenção psicossocial, fosse possível a construção da autonomia mediante responsabilização compartilhada e pactuada entre os sujeitos, os serviços e a comunidade. 
O cuidado ao sujeito possibilitou explorar potências que puderam ser estabelecidas a partir de práticas assistenciais construídas entre a equipe que atuou no momento da internação. Foi importante, portanto, priorizar o acolhimento, a autonomia e a troca direta com as experiências de vida do indivíduo que possui um lugar no mundo, uma história.

O objetivo deste trabalho, portanto, foi analisar as práticas assistenciais oferecidas às pessoas em sofrimento psíquico durante internação em hospital especializado em psiquiatria. Tal estudo visou contribuir com a reflexão acerca do cuidado prestado aos sujeitos internados nos hospitais psiquiátricos e do aprimoramento deste cuidado a partir do questionamento do modelo assistencial institucional. Os diferentes modelos assistenciais possibilitaram reconfigurar a lógica de atenção psicossocial, a partir de práticas asilares ou ampliá-las à medida que sejam pautadas no diálogo com a RAPS e seus pressupostos de singularização e territorialização do cuidado.

\section{Resultados e Discussão}

"A tomada de consciência que passa do vivido ao pensado não termina o conhecimento, ela faz parte dele; pois o estabelecimento dos conceitos não anula a dimensão e a incursão do imaginário.”

\section{Canguilhem}

Nomeei "Espaço (hi)Ato" esta complexidade da percepção do profissional sobre o impacto da sua atuação no cuidado aos usuários internados o termo

\section{Trechos do DC:}

[...] um paciente veio ao portão do posto e diz que queria passar por ali, pois segundo ele, acabara de ligar para seu pai e este estava conversando com seu médico. Ele queria ver o pai e participar da conversa. A equipe respondeu que ele precisava esperar alguém chamá-lo. O paciente insistiu. Tentou abrir a porta. O paciente chutou o portão. Mesmo com todo o barulho, a técnica de enfermagem (TE) precisou chamou o plantão médico, localizado ao lado do posto de enfermagem. O residente médico (RM) tentou abordá-lo verbalmente, insistiu que ele precisava tomar uma medicação e que ele não poderia ter quebrado a cadeira. O paciente continuou gritando, xingou a equipe, disse que iria embora de qualquer jeito. O médico comunicou a equipe que precisava contê-lo, enquanto prescrevia a medicação injetável. Ele então foi contido mecanicamente por 3 TE em 4 pontos no leito clínico e a injeção foi aplicada na sua perna direita. Em poucos minutos o pai do paciente foi até ele se mostrando contrariado com a conduta. O paciente se acalmou em conversar com o pai. A residente multidisciplinar que acompanhava a conversa com o pai, soltou a contenção do pé (o paciente se queixou de estar apertada) e perguntou se poderia retirar toda a contenção para conversarem no consultório. A $(E)$ chegou neste momento e perguntou o que tinha ocorrido, disse que estava no telefone com o paciente e que ele havia acabado de falar com o pai. O médico assistente do paciente perguntou à equipe de enfermagem o que achavam sobre a contenção e percebendo o impasse, diz que o paciente precisava ficar mais tempo, esperar a medicação fazer efeito. O paciente chorou e disse ao pai que queria ir embora, o pai disse que ele não poderia ter agido daquela forma[...] (14/08/2019). Durante o tempo em que realizei a observação participante pude presenciar outros quatro episódios semelhantes próximo à porta do posto de enfermagem, em que a intervenção se deu com o sujeito medicado e contido mecanicamente no leito clínico.

\section{O impacto do cuidado na atuação no trabalho}

a) A busca pela ética do cuidado: 
Mais da metade dos entrevistados afirmaram que suas atuações no trabalho foram pautadas na lógica da atenção psicossocial, caracterizadas pelo acolhimento, escuta, vínculo, construção de redes territoriais, cuidado integral, ético, focado na produção de vida.

O cuidado centrado no sujeito e em sua complexidade impactou na construção de direcionamentos e permitiu com que ele exerça através da sua forma de estar no mundo, sua cidadania e liberdade.

"busquei oferecer um cuidado compartilhado, integral, pois só assim o impacto na vida do paciente é melhor ... e com direcionamento ético focado na produção de vida dos usuários” $R 2$

"acredito na importância da escuta de um sintoma que vá além da psicopatologia, mas como modo de organização...de estar no mundo” P1

"acolho quando posso estar disponivel, fazendo com que ele se sinta tranquilo, mais seguro...recolho angústias, pensando com ele outras formas de estar na vida...não reinterne" E1

"busco a autonomia dos usuários, quem é, de onde veio, pra onde vai, quais vínculos... me preocupo com isso” A1

A responsabilização com a saúde foi além do atendimento propriamente dito, pois dizia respeito também ao vínculo necessário entre profissional e usuário, estimulando a autonomia e a cidadania.

O vínculo é uma diretriz que, acoplada ao acolhimento, é capaz de garantir o real ordenamento do processo de trabalho, ou seja, um arranjo tecnológico que propõe reorganizar o serviço, garantindo acesso aos usuários, com o objetivo de escutá-los, resolver seus problemas mais simples, além de proporcionar um atendimento humanizado (Merhy, 2014).

A construção do vínculo foi um recurso terapêutico essencial da clínica, portanto, não se tratava somente de uma preocupação humanizadora, mas também do estabelecimento de uma técnica que qualifique o trabalho em saúde (Milhorini, Montezeli, Célia, \& Rezende, 2021).

Assim, o vínculo é fundamental no serviço de saúde, pois propicia ao usuário exercer seu papel de cidadão, conferindo-lhe maior autonomia no que diz respeito a sua saúde, tendo seus direitos de fala, argumentação e escolhas respeitados, permitindo ao profissional conhecer o usuário para que colabore com a integração dele na manutenção da sua saúde e redução dos agravos (G. W. de S. Campos, 2013).

No contexto da saúde, essa tecnologia foi, antes de tudo, relacional e se produz nas trocas afetivas relacionais; no emprego de uma atitude de zelo e desvelo para com o outro. Essa relação pulsante aconteceu em ato, quando o agente assumiu para si uma atitude de implicação, (pre)ocupação e (co)responsabilização com a demanda apresentada (Merhy, 2014). Este cuidado, segundo alguns entrevistados, deveria ser uma prática desempenhada por todos os profissionais que atuam na saúde mental, porém o elevado número de pacientes internados, a configuração do processo de trabalho e a rigidez das rotinas impediam a exploração de novas possibilidades de cuidado.

"gosto de atuar em saúde mental, toda a minha formação se deu nessa área, mas fico frustrada por perceber que são apenas poucos pacientes que a gente consegue se aproximar, investir de verdade...pelo grande número de pacientes e ainda mais pela constituição do plantão em escalas" E4 
O hospital psiquiátrico é massificado, não existe a individualidade, pelo contrário, os grupos de internados eram grandes, as pessoas eram tratadas da mesma forma, obrigadas a fazerem a mesma coisa. Os horários eram impostos. As pessoas que ali trabalharam não sabem como lidar com a desordem e com o inesperado, elementos corriqueiros no dia a dia das pessoas com problemas de saúde mental (Pitta, 2016).

Podemos observar que, a manifestação de sentimentos de frustração nas práticas profissionais relacionou-se, ao que parece, à idealização de que seu investimento profissional geraria resultados transformadores, imediatos e definitivos na vida do usuário. A pessoa atendida passou ser depositária da expectativa decorrente do investimento profissional em um trabalho não implicado à ideia de equipe interdisciplinar. Esse relato pode ser aproximado de uma concepção norteada pelo paradigma biomédico, que pressupõe expectativas de comportamentos, norteada pela visão de homem ideal e não real, segundo a racionalidade positivista que direciona esse modelo tradicional de assistência (Furtado et al., 2017).

Através das falas dos profissionais foi possível perceber que a disponibilidade para construção de um cuidado integral, que priorizou o acolhimento do sujeito internado levando em consideração sua subjetividade e autonomia, não foi eficaz devido à falta de uma equipe interdisciplinar.

Uma entrevistada identificou que houve um impacto muito positivo no cuidado através da participação da equipe interdisciplinar em atividades coletivas. Ainda que a equipe necessitasse de frequentes convocações para a constituição deste espaço terapêutico que pudesse transcender a lógica asilar e não reduzir o sujeito ao sintoma, e sim produção de formas de estar no mundo.

"preciso de suporte devido à grande demanda...é preciso uma equipe formada por diferentes categorias que ajudem a construir o cuidado" E1

“... me vejo importante em relação à atuação nas atividades coletivas, mas só tem efeito porque é compartilhado...não dá pra fazer sozinha ... no começo foi difícil construir esse coletivo, mas fui chamando e os outros foram indo... é caótico, ninguém me mostrou, fui aprendendo" P1

Percebemos que o entendimento sobre a interdisciplinaridade expressava a ideia de integrar, compartilhar, contar com a ajuda de outro profissional. Para esses profissionais, a interdisciplinaridade era uma forma de ampliar seus horizontes, o que permitiria o fim da visão restrita disciplinar e incluiria outras dimensões das situações trabalhadas.

Como construção imprescindível, surge a ideia de unicidade, que impulsionava o profissional a obter melhor conscientização dos limites e das possibilidades de cada campo de saber e o fazia ter maior abertura ao trabalho coletivo, que surgia (Costa-Rosa, 2016) .

O autor ainda afirmou que a interdisciplinaridade só podia ser realizada por meio da intencionalidade, baseada no plano institucional, que podia fomentá-la com políticas e projetos, mas também, e principalmente, com o desejo de cada profissional de aderir a esses projetos e de se engajar na construção da prática coletiva. A postura interdisciplinar exigia trocas entre os profissionais e abertura para questionar e ser questionado quanto ao respeito ao reconhecimento mútuo.

\section{b) Rupturas e fragmentações no cuidado}

Sobre a forma de atuação no cotidiano do trabalho, dois entrevistados médicos concursados consideraram que o cuidado ao sujeito internado se deu indiretamente, ao desempenharem o papel de supervisores médicos. Com isso, as condutas e atuações dos residentes foram orientadas por tomadas de decisões do supervisor médico. 
"acho que meu trabalho impacta sim, através da supervisão... tenho que sinalizar sobre o atendimento ao sujeito e sobre as relações com outros profissionais... isso vai refletir de alguma forma no paciente” S1

"as decisões que se toma em supervisão acabam impactando na vida do sujeito, às vezes alguém tem que dar a palavra final” $S 2$

Importante ressaltar que este estudo teve como cenário um hospital psiquiátrico universitário, ou seja, um espaço de formação associado à assistência prestada pela residência médica e multiprofissional, que se diferenciam entre outros aspectos, pelo conteúdo curricular e sua abordagem sobre o conceito de doença mental.

Deve-se ampliar a noção de formação para que seja possível superar as compreensões reducionistas, possibilitando sua transcendência como experiência humana num permanente movimento de procura, construção e crítica, tornando-se epistemológica (Freire, 2019).

Portanto, quando falamos de formação como referência cultural e epistemológica, não nos referimos a um simples treinamento, adestramento, transferência de conhecimento, mas de emancipação, criação de potência, de projetos, de perspectiva crítica.

Os sujeitos que atuam em saúde mental poderiam receber, em sua formação, reflexões mais amplas, mais problematizadoras, sobre a complexidade humana, sobre a produção de sentidos das atividades essencialmente humanas.

Foi questionada a manutenção de programas de formação nos moldes de residência estritos à espaços hospitalares, e sugeriu que tais programas se deem de forma intensiva nos territórios, participando de formulações e controle social do SUS (Amarante, 2019). O autor defendeu que se amplie o conceito e prática de reforma psiquiátrica para compreensão do processo social complexo sem reduzi-la a simples reformulação de serviços, mas que enfrentasse espaços conceituais da psiquiatria, sua função de controle na sociedade, suas articulações com a justiça e interesses mercadológicos e exploratórios existentes neste campo. Alguns entrevistados entenderam que o cuidado em saúde mental ultrapassa a especificidade do profissional e a especificidade formal da própria clínica e deve ser centrado na singularidade do individuo internado.

"é diferente do que estava acostumado no hospital clínico, aqui a gente não tem protocolo, se tiver não é o ideal, dois pacientes com a mesma patologia têm demandas diferentes, diferente do hospital clínico” T2

Os profissionais foram estimulados a se "super - especializarem" com o aprendizado e a ler fragmentos da realidade. Os médicos aprenderam a medicar e a ver na medicação a solução primeira para qualquer tipo de situação; os psicólogos aprenderam a realizar uma terapia centrada no indivíduo e em seu sofrimento privatizado; os enfermeiros a se ocuparem com a administração de medicações e higiene, etc.

No entanto, nenhum desses profissionais aprendeu a lidar com as situações cotidianas dos usuários, como, por exemplo, impasses na subjetividade das pessoas e seu sofrimento, na maioria das vezes, desencadeados pelo cotidiano, que se desenrola em duras condições sociais.

Esses profissionais foram incapazes de ouvir o sujeito e sua dor além da doença, de forma que articulasse os sintomas e sinais em um quadro mais amplo e complexo; raramente estabeleceram diálogos que produzissem uma integração com outros profissionais que trabalharam a seu lado; não compreenderam as dificuldades das pessoas em aderir ao tratamento estruturado dessa forma; estranharam e se incomodaram com as reivindicações das pessoas a respeito de seus direitos; apresentaram 
grandes dificuldades em construir estratégias que ampliassem a participação e autonomia dos usuários (Furtado et al., 2017).

A mudança de paradigma não era uma agenda específica da Saúde Mental. Pelo contrário, ela se incluiu no conjunto de transformações práticas que tinham como prioridade a construção do SUS no contexto da Reforma Sanitária.

Alguns entrevistados apontaram a dificuldade em lidar com o sofrimento psíquico do outro, este que é diferente da clínica médica e não tem cura, no sentido cirúrgico de uma solução, mas requer um cuidado criativo, provisório, integral, intersetorial e capaz de sustentar o sujeito em sua complexidade como um cidadão em liberdade.

"às vezes acho que meu trabalho é enxugar gelo, eu já investi muito, talvez não fosse da maneira correta, mas daqui a pouco ele está aqui de novo... isso desestimula um pouco... diferente de uma pneumonia” E5

O modelo psicossocial não almejou a supressão sintomática, o que se visou diretamente pode ser descrito com os termos "reposicionamento subjetivo", uma vez que se procurará levar em conta a dimensão subjetiva e a sociocultural (CostaRosa, 2016).

Nesse sentido, o fato de que a doença não ocupa todo o lugar do sujeito, não o desloca totalmente de todo o cenário social no qual está inserido. Ele sempre é um sujeito multifacetado e não restrito apenas aos aspectos biológicos, ele também tem em sua integridade um ser social, histórico e subjetivo, que demanda outras necessidades e necessita ser abordado nas suas diversas dimensões (R. O. Campos, 2001) .

Outro entrevistado apontou que outras formas de abordagens em situações de crise, que contassem com equipe interdisciplinar, poderiam diminuir a necessidade do uso de força física para realização de contenções mecânicas. Para criar novas possibilidades de cuidado singularizado que possam ir além das normas institucionais, como a própria contenção químico-física, seria importante o treinamento contínuo e atualização do conhecimento.

“estou sempre aberto ao conhecimento, próximo à academia e de enfermeiros que pensam na melhoria do cuidado ... tento sempre melhorar a vida institucional da pessoa... tem pessoas que só dão medicação dentro do posto, pro sujeito que não conseguiu dormir a noite eu posso ir lá no leito dar a medicação dele, esse é um outro olhar ... em relação à contenção mecânica, se outras pessoas estiverem junto, podem agir e participar de outra forma... é uma visão de todos da equipe acionar alguém que tenha mais força na hora da contenção” T3

Para que o cuidado em saúde mental pudesse ser posto em prática, deve-se superar o viés estritamente biomédico, fragmentado, normatizado e maniqueísta.

Faz-se necessário ressaltar que os usuários, enquanto redes de existências, produzem-se 'em-mundos', 'in-mundizamse', constituindo certas formas éticas existenciais e certos modos de conduzir, por si, também a produção de cuidado, disputando o tempo inteiro com as outras diferentes lógicas de existir, em si, e que lhes foram impostas pelas instituições. Os usuários produziam modos de existências que eram, muitas vezes, julgados e cerceados pelas equipes de saúde, e estas ficavam aprisionadas a um modo de saber tão preponderante, que não possibilitou perceber que certas atitudes, comportamentos, expressões são modos de existência, ainda que se apresentem cheios de tensões e problemas (Merhy, Paula, Gomes, Silva, \& Fátima, 2014). 


\title{
II. Residência multiprofissional e o impacto na assistência.
}

A contínua transformação da melhoria da assistência, para a maior parte dos entrevistados, estava diretamente relacionada à inserção da residência multiprofissional no cerne das direções "não-médicas" e "extra - clínicas" de suma importância na vida "em ato" (em contraposição ao recorte gerado durante a internação em que foi afastado do seu meio social/familiar) dos sujeitos internados, provocando fortes impactos, tanto na intervenção e forma de cuidado voltado para o modelo da atenção psicossocial, quanto na influência na formação da residência médica.

Tais mudanças foram consideradas positivas, pois o "trabalho fora-muros" (também conhecido como o próprio "furo-no-muro" - termo utilizado e também questionado pelos residentes multiprofissionais) foi fundamental para abreviação da permanência do sujeito internado no hospital, redirecionando o ainda vigente modelo médico-centrado para o da lógica de cuidado no território.

\begin{abstract}
"houve mudanças na articulação com a rede quando se institui bolsas para residência multiprofissional ... a intervenção e forma de ver o paciente passaram a ser diferentes, o serviço social não dava conta sozinho ... houve uma mudança radical na avaliação de fatores não médicos e na formação do médico" S1
\end{abstract}

"percebo que a assistência tem estado mais voltada para a escuta do usuário, principalmente em relação à equipe multi" T1

"o hospital ao longo do tempo mantém a mesma infraestrutura, houve a mudança com a chegada das residentes multiprofissionais para atender os pacientes" S2

"estou aqui há pouco tempo, acho que a assistência é boa, mas falta um conectivo entre os saberes, acho que a residência multiprofissional discute mais do que as outras categorias" A1

"aqui as práticas de modelo tradicional, verticalizado, médico-centradas vêm sendo transformadas pela residência multiprofissional através dos NATIs" T3

$\mathrm{Na}$ abordagem clássica da formação em saúde, o ensino caracterizou-se tecnicista e preocupado com a sofisticação dos procedimentos e do conhecimento dos equipamentos auxiliares do diagnóstico, tratamento e cuidado, planejado segundo o referencial técnico-científico acumulado pelos docentes em suas respectivas áreas de especialidade ou dedicação profissional.

No campo da saúde mental, as formações tradicionais por vezes realizaram abordagem rasas sobre aspectos desafiadores da clínica no cotidiano dos serviços, sobre a Reforma Psiquiátrica Brasileira e sobre as práticas inovadoras no campo da Atenção Psicossocial. A grade curricular da residência multidisciplinar apontou uma ampliação neste campo, entendido aqui, como modelo de cuidado em liberdade, de trabalho territorial, de produção de autonomia, garantia e exercício de direitos.

Os modelos de cuidado (manicomial e psicossocial) se entrelaçaram num mesmo espaço configurando uma espécie de arena de disputa de saberes. A reprodução acrítica das dicotomias sujeito/objeto, teoria/prática, interior/exterior acabou buscando uma orientação "protocolar e burocrática" que pode ser tanto com operações de estabilização e supressão dos sintomas, como a "mapeamento da rede e a "escuta-surda" do sujeito que precisou ter alta hospitalar custe o que custar, sem a construção do cuidado necessário para evitar maiores sofrimentos ou, possivelmente, o breve retorno à internação. 
O cuidado em saúde mental deve ser vivenciado mediante configurações em redes que ampliem as possibilidades de acolhimento do usuário e de seus familiares, potencializando o exercício da cidadania e da inclusão social (Ayres, 2004).

\section{Conclusão}

O presente estudo atingiu seu objetivo ao analisar as percepções dos profissionais sobre o impacto que suas atuações exercem no cuidado aos usuários internados em um hospital especializado em psiquiatria. O recorte metodológico realizado para uma pesquisa qualitativa e etnográfica baseada em entrevistas e observação sistemática mostrou-se adequado para guiar a coleta de dados. A utilização do referencial teórico baseado em Amarante, Basaglia, Onocko, Pitta e Menhy permitiu analisar e melhor visualizar o muro e as passagens da instituição hospital.

O cuidado prestado pelos profissionais visou superar o viés biomédico, fragmentado, normalista e maniqueísta, onde a assistência foi centrada na racionalidade cientifica moderna, na biomedicina e no biopoder.

O cuidado foi voltado para a resolutividade e a noção de "cura" produziu mal-estar profissional na medida em que a cronificação se mostra como falência dos esforços terapêuticos. A questão da cura seguiu controversa na comparação com outras clínicas, e trouxe um certo desalento de "enxugar gelo", um sempre recomeçar, pelas muitas reinternações, não conseguiram ver que a falha é dos dispositivos de cuidado e não pessoal.

A inexistência de uma equipe interdisciplinar para construir diferentes formas de cuidar foi percebida através da fala dos entrevistados, prevalecendo, numericamente, a velha dupla do hospício, enfermagem e médicos. Os supervisores médicos avaliaram que detinham "a palavra final" sobre o paciente.

A escala da enfermagem, seguiu sendo uma dificuldade estabelecida para a participação nos colegiados de supervisão a fim de compartilhar saberes e direções de cuidado.

O cuidado pautado no vínculo e articulado com território foi remetido aos residentes multiprofissionais, que marcaram a assim chamada assistência "furo no muro", determinando um papel fundamental na abreviação do tempo de internação, além de propor escuta aos usuários, discussões sobre casos clínicos e transformações de práticas médico - centradas.

A mudança do conceito de saúde mental abandonou a assistência centrada na doença e adotou o enfoque na produção de saúde, no resgate da cidadania e na participação social. Assim, ampliou os espaços terapêuticos para o território e passou-se a buscar a desinstitucionalização e reabilitação psicossocial. As ações terapêuticas ocorreram nas inter-relações entre subjetividade, gestão dos processos de trabalho e clínica. O cuidado, nesta perspectiva, exigiu conhecimento técnico e comprometimento sociopolítico, habilidade em lidar com a diferença e responsabilidade com a vida de cada pessoa que o busca, motivação profissional e valorização do seu trabalho. A solidez esteve alicerçada no questionamento, na reflexão e, sobretudo, nas relações interpessoais dialógicas. Essas características articularam-se com o compartilhamento das ideias da Reforma Psiquiátrica e com uma prática cotidiana crítica, reflexiva e criativa (Nunes, Torrenté, Ottoni, Moraes Neto, \& Santana, 2008).

A busca por um novo fazer na clínica, possibilitou uma compreensão mais ampliada da vivência de quem sofre. Neste sentido, refletir sobre o que baliza este novo cuidado e esta nova clínica nos colocou em um lugar de constante busca e compreensão.

Apresentamos neste artigo as premissas para o caminho do cuidado em Saúde Mental como partindo do território, do cuidado para além da administração dos fármacos (desinstituicionalização), do empoderamento do sujeito em sofrimento psíquico e do trabalho em equipe com uma postura respeitosa e agregadora. 
Research, Society and Development, v. 10, n. 10, e143101017531, 2021

(CC BY 4.0) | ISSN 2525-3409 | DOI: http://dx.doi.org/10.33448/rsd-v10i10.17531

\section{Referências}

Amarante, P. (2019). Saúde menetal e atenção psicossocial. (Fiocruz, Ed.), Cad. Saúde Pública (4th ed.). Rio de janeiro.

Amarante, P., \& Nunes, M. de O. (2018). A reforma psiquiátrica no SUS e a luta por uma sociedade sem manicômios. Ciência \& Saúde Coletiva, 23(6), 20672074. https://doi.org/10.1590/1413-81232018236.07082018

Ayres, J. R. M. (2004). O cuidado, os modos de ser (do) humano e as práticas de saúde. Saúde e Sociedade, 13(3), 16-29. Retrieved from http://www.scielo.br/pdf/sausoc/v13n3/03.pdf

Brasil. Portaria ${ }^{\circ} 3.088 / 2011$ (2011).

Brasil, ministério da saúde. Reforma Psiquiátrica e política de Saúde Mental no Brasil. (2005).

Campos, G. W. de S. (2013). A clínica do sujeito: por uma clínica reformulada e ampliada. (Hucitec, Ed.). São Paulo.

Campos, R. O. (2001). Clínica: a palavra negada: sobre as práticas clínicas nos serviços substitutivos de saúde mental. Saúde Debate, 5(58), 98-111.

Costa-Rosa, A. da. (2016). Atenção psicossocial além da reforma psiquiátrica: contribuição a uma clínica crítica dos processos de subjetivação na saúde coletiva. (Unesp, Ed.). São Paulo.

Freire, P. (2019). Pedagogia da autonomia: Saberes necessários à prática educativa. (P. \& Terra, Ed.) (68th ed.). São Paulo.

Furtado, R. P., Sousa, M. F. de, Martinez, J. F. N., Rabelo, N. S., Oliveira, N. S. R. de, \& Simon, W. de J. (2017). Desinstitucionalizar o cuidado e institucionalizar parcerias: desafios dos profissionais de Educação Física dos CAPS de Goiânia em intervenções no território. Saúde e Sociedade, 26(1), 183195. https://doi.org/10.1590/s0104-12902017169101

Merhy, E. E. (2014). A cartografia do trabalho vivo. (Editora Hucitec, Ed.) (4th ed.).

Merhy, E. E., Paula, M., Gomes, C., Silva, E., \& Fátima, M. De. (2014). Redes Vivas : multiplicidades girando as existências , sinais da rua . Implicações para a produção do cuidado e a produção do conhecimento em saúde, (August 2016).

Milhorini, C. R., Montezeli, J. H., Célia, R., \& Rezende, B. (2021). Representações sociais de acadêmicos de enfermagem sobre a empatia no cuidado: Abordagem ao paciente queimado Social representations of nursing academics about empathy in care: Approach to burned patients Representaciones sociales de los académicos de e. Research, Society and Development, 9(9), 1-9.

Minayo, M. C. S. (2016). Pesquisa social: teoria, método e criatividade. (Editora Vozes, Ed.), Minayo, M.C.S (Org.) Pesquisa Social: teoria,método e criatividade (34th ed.). Petropolis.

Nunes, M., Torrenté, M. de, Ottoni, V., Moraes Neto, V., \& Santana, M. (2008). A dinâmica do cuidado em saúde mental: signos, significados e práticas de profissionais em um Centro de Assistência Psicossocial em Salvador, Bahia, Brasil. Cadernos de Saúde Pública, 24(1), 188-196. https://doi.org/10.1590/s0102-311x2008000100019

Pitta, A. M. F. (2016). O que é a reabilitação psicossocial no Brasil, hoje? In Reabilitação Psicossocial no Brasil. São Paulo.

Sampaio, J. J. C., Guimarães, J. M. X., Carneiro, C., \& Garcia Filho, C. (2011). O trabalho em serviços de saúde mental no contexto da reforma psiquiátrica: um desafio técnico, político e ético. Ciência \& Saúde Coletiva, 16(12), 4685-4694. https://doi.org/10.1590/S1413-81232011001300017 